\title{
Conducting a Community Forum to Address Youth Substance Abuse ${ }^{1}$
}

\author{
Emily Rickerson, Muthusami Kumaran, and Kate Fogarty ${ }^{2}$
}

This article is intended to serve as a basic overview for conducting a community forum on youth substance abuse. The community forum format that will be discussed in this article comes from the National Issues Forums (NIF) model, which involves using a moderator to facilitate the forum. Suggestions will be made on how to lead and conduct a forum on youth substance abuse, based on the NIF model (see Resources section to find more information on the NIF model and guidebooks used).

Youth substance abuse in the United States is a prominent issue, as over 70 percent of high school students have consumed alcohol at some point in their lifetime; over 35 percent of high school students have tried marijuana; and over 45 percent have smoked a cigarette (Youth Risk Behavior Surveillance Survey 2009). Community forums can be a beneficial tool in helping to discover the specific needs of a community and finding a solution that will best serve in working towards resolving the issue at hand.

Community forums are about participatory democracy at a local level (Khamis 2000). They involve gathering citizens of a community together to discuss issues, make choices on how to deal with them, and develop common ground to resolve those issues.

There are several ways to conduct a community forum:

- meetings with community members involving a facilitator (addressed in this article)
- meetings involving panelists of community members

- online forums (online space for discussions where members can hold conversations on certain topics without having to meet face-to-face)

The following are suggestions for conducting a community forum using a facilitator.

\section{Moderator's Role}

The moderator's role is facilitation, not participation. The steps a moderator should take in conducting a community forum are as follows:

- Participant sign-in when entering

- Strategic seating arrangements so that partisan groups or factions are less likely to form

- Welcome and overview of discussion topic (Note: Forums work best when moderators address one specific substance related issue at a time, i.e., focus on one topic such as underage drinking instead of multiple avenues of substance abuse.)

- Pre-forum questionnaire (optional)

- Statement of ground rules (that all participants will abide by)

1. This document is FCS9266, one in a series of the Department of Family, Youth and Community Sciences, Florida Cooperative Extension Service, Institute of Food and Agricultural Sciences, University of Florida. Published August 2011. Visit the EDIS website at http://edis.ifas.ufl.edu.

2. Emily Rickerson, graduate assistant; Muthusami Kumaran, assistant professor; Kate Fogarty, assistant professor; Department of Family, Youth and Community Sciences; Institute of Food and Agricultural Sciences; University of Florida; Gainesville, FL 32611. 
- Provide participants with facts on the issue (in order to set the stage for the deliberative process)

- Have participants share experiences with issue

- Facilitate deliberation process (guide the flow of conversation, ask questions, state options that arise, keep track of time)

- Reflection period

- Discuss steps that need to be taken next (set up next meeting)

- Post-forum questionnaire (optional)

- Develop a report of what was discussed for documentation

The NIF model focuses on deliberation rather than discussion or dialogue. The moderator's role during a forum is to lead the deliberation process. The moderator must (National Issues Forums Moderator Guide 1998):

- guide the flow of conversation, looking at costs and consequences of options presented;

- make sure all options are considered by looking at the positive side of each option (to ensure options are not dismissed at first glance);

- encourage dialogue and youth voice on the topic;

- make sure youth are proportionally represented in the forum and that their views are respected by all forum participants;

- recognize and address the fact that forums rarely end with everyone in total agreement; and

- stay with the deliberation until members understand the options best suited for the community and address the conflicts that go along with those options.

Although the moderator must lead the conversation, she/ he must be careful not to offer her/his own opinions on the subject matter or compliment participants on their views (National Issues Forum Institute 2001).

\section{Beginning the Process}

The moderator should start the meeting welcoming those who attend and giving a brief overview of the topic at hand. It is best to conduct a forum in a large, open room, arranging the chairs in a circle so participants can face each other during discussions (National Issues Forums Institute 2001). A pre-forum questionnaire (see Appendix A) may be used to get an idea of the views of the participants before the forum begins in order to receive initial thoughts on the subject. A post-forum survey (see Appendix B) can also be conducted to identify final thoughts on the issue.

After the initial welcome and pre-forum questionnaire, the moderator should state the ground rules for the forum and emphasize that the forum is not for a debate, and is meant to work towards making a decision on an important community issue. Some of the rules to follow include:

- list the pros and cons of every option (costs and consequences);

- state the facts of each option;

- develop an understanding of the deeper motivations behind people's opinion (what people find most important to them in everyday life);

- embrace the views of others and work through conflicts that arise (National Issues Forums Moderator Guide 2000).

Providing participants with information on the subject matter at the beginning of the meeting is a good way to get everyone focused on the issue and prepared with a knowledge base (see Appendix $C$ for a youth substance abuse fact sheet). Statistics on issues such as youth substance abuse can also make participants blatantly aware of the problem at hand. Seeing such high numbers of youth involved in substance abuse can create a sense of urgency in acting upon the problem. (For example, you can look at the Florida Youth Substance Abuse Survey and find data specific to counties, which all states collect to some degree in local venues.) The moderator should also encourage participants, especially youth participants, to share how the issue has affected them or anyone they know personally. This will make the issue seem more human rather than something abstract (National Issues Forums Moderator Guide 2000). Discussing specific cases of how youth substance abuse is affecting the community can bring to light the importance of the subject matter and make participants more involved in the forum.

According to the National Issues Forums Moderator Guide 1997-1998, when conducting a deliberation, four basic questions should be asked throughout the process: 
1. What is valuable to us (all participants and youth voice emphasized)?

2. What are the costs or consequences associated with the options?

3. What are the conflicts in the issue that we have to work through?

4. Can we find any shared sense of purpose or define how our interdependence is grounds for action?

During the deliberation, the moderator will need to keep track of time. Participants in the forum have their own time constraints with family and work, and if the meeting runs too long, they may leave, resulting in a loss of opinions represented. Moderators need to stick to the allotted time to discuss items and move things along in such a way that no one voice dominates the deliberative process. In addition, the best times for meetings that work for participants of all ages are usually at the end of the workday between 5:30 and 7:30 PM (Washington State Board of Health 2009).

\section{Reflection}

Before ending the forum, it is important to leave time for reflection. Reflection gives participants an opportunity to look back on what they have learned and to assess how the process may have changed their thinking. It can also segue into what should happen next or a call to action. The moderator needs to discuss what steps should be taken in the future as a result of the forum discussion and when or if the group wants to meet again for further collaboration.

Before leaving the forum, documentation of all participants who attended should be recorded. It is important (if applicable) that the information discussed should also be recorded and reported to the community so that interest and action to resolve the issue will continue beyond the forum.

\section{References}

Florida Youth Substance Abuse Survey (2010). Florida Department of Children and Families. Retrieved May 23, 2011 from http://www.dcf.state.flus/programs/samh/ publications/fysas/10Survey/2010_FYSAS_Statewide_Tables_(Final).pdf.

Khamis, C. (2000). Establishing Community Forums that Make a Difference. Local Economy 15(3):264-267.
National Issues Forums Institute, 2001. National Issues Forums in the Classroom, A High School Program on Deliberative Democracy. Dayton, Ohio.

National Issues Forums Moderator Guide 1997-1998. Illegal Drugs. National Issues Forums Research, Dayton, Ohio.

National Issues Forums Moderator Guide 1999-2000. Alcohol. National Issues Forums Research, Dayton, Ohio.

Washington State Board of Health, 2009. Community Forums: Food, Fitness, and Our Kids. Retrieved October 22, 2010 from http://www.sboh.wa.gov/Goals/Past/SPAN/Tips. htm

Youth Risk Behavior Surveillance Survey United States (2009). Department Of Health And Human Services, Centers for Disease Control and Prevention. Retrieved October 20, 2010, from: http://www.cdc.gov/mmwr/pdf/ss/ ss5905.pdf.

\section{Appendix A}

Sample Pre-forum questionnaire taken from the National Issues Forum Institute's National Issues Forums in the Classroom, A High School Program on Deliberative Democracy Teachers Guide, 2001

\section{What I Think Now (Before the Forum)}

Directions: Use the space below to record your thoughts and opinions about the issue that will be the focus of the forum. Your notes will help you keep track of your thoughts over the course of the forum. Remember, the goal of a forum is not necessarily to change your mind but to increase your understanding of your own opinions and ideas and those of others.

1. Right now, these are my thoughts and opinions about the issue:

2. During the forum, I want to learn the following about the issue:

3. At this point, I think that the best approach to the issues is...

4. I do/do not (circle one) expect my ideas about the issue to change because...

5. At this time, I think that people who disagree with me should consider the following points or ideas: 


\section{Appendix B}

Sample Post-forum questionnaire taken from the National Issues Forum Institute's National Issues Forums in the Classroom, A High School Program on Deliberative Democracy Teachers Guide, 2001

\section{What I Think Now (After the Forum)}

Directions: Use the space below to record your thoughts about the issue that was the focus of the forum.

1. If someone were to ask me about the issue, this is what I would tell them:

2. Right now, this is what I think about the issue:

3. My ideas about the issue changed/did not change (circle one) because...

4. I think that the most difficult part of making trade-offs and choices is...

5. The most important thing that I learned from participating in the forum is...

\section{Appendix C: Youth Substance Abuse Facts}

\section{U.S. Youth Substance Abuse Facts}

Source: Youth Risk Behavior Surveillance Survey, 2009

Youth surveyed consisted of students grades 9-12 nationwide (50 states and the District of Columbia) from regular public and private schools.

- $46.3 \%$ of students had ever tried cigarette smoking in their lifetime

- $11.2 \%$ of students had ever smoked at least one cigarette every day for 30 days

- $72.5 \%$ of students have had at least one drink of alcohol in their lifetime

- $41.8 \%$ of students have had at least one drink of alcohol on at least 1 day during the 30 days before the survey

- $21.1 \%$ of students had drunk alcohol (other than a few sips) for the first time before age 13

- $36.8 \%$ of students had used marijuana one or more times during their lifetime
- $20.2 \%$ of students had taken prescription drugs (e.g., Oxycontin, Percocet, Vicodin, Adderall, Ritalin, or Xanax) without a doctor's prescription one or more times during their lives

\section{Florida Youth Substance Abuse Facts}

Source: 2010 Florida Youth Substance Abuse Survey

Youth surveyed consisted of male and female students age 11-18 in grades 6-12 in the state of Florida. Data was collected in 2010.

- Over 50\% of youth reported using alcohol in their lifetime

- Over $25 \%$ of youth reported using cigarettes in their lifetime

- Over $20 \%$ of youth reported using marijuana or hashish in their lifetime

- $29 \%$ of male and $25.3 \%$ of female high school students reported using alcohol at age 13 or younger

- $18.3 \%$ of male and $15.9 \%$ of female high school students reported using cigarettes or marijuana at age 13 or younger 